\title{
Traditional VERSUS OPEN-BOOK EXAMS IN REMOTE COURSE DELIVERY: A NARRATIVE REVIEW OF THE LITERATURE
}

\author{
Anita M. Parker, Ellen Watson,, Nicole Dyck, Jason P. Carey 1 \\ ${ }_{1}$ Faculty of Engineering \& ${ }_{2}$ Centre for Teaching and Learning, University of Alberta, Edmonton, Alberta \\ aparker@ualberta.ca,jpcarey@ualberta.ca
}

\begin{abstract}
Assessment is an essential step in the teaching and learning process. Traditional examination methods (closed-book, time-constrained, invigilated, multiplechoice) prevail in higher education despite support for alternative approaches wherein students construct knowledge through active, authentic activities. A review of the scholarly literature focused on merits and limitations of traditional closed-book exams in-person and in an online, remote course delivery context, as well as benefits, concerns, and considerations of transitioning to open-book exams at a time of upsurge in online learning. Within the dichotomy of traditional versus alterative exam strategies, the literature is inconclusive on shared matters, including student academic integrity, study habits, anxiety, performance, and long-term retention of information.
\end{abstract}

Keywords: Assessment in higher education, traditional assessment(s) or exams, alternative assessment(s), openbook exams, academic integrity or cheating

\section{INTRODUCTION}

Assessment of student learning in higher education is intrinsic to the teaching and learning process. Effective assessments align with learning goals and provide direct evidence of student achievement.[1] Assessment is central to the student experience, a way to engage meaningfully with course content, and can evoke an array of negative emotions, such as fear, dread, anxiety, and intimidation, or even positive emotions, such as confidence and optimism.[2, 3, 4,5]

Traditional exams are characteristically closed-book, invigilated, time-constrained, and may consist primarily of multiple-choice style questions. $[1,6]$ Alternative ways of measuring student knowledge and skills are a departure from traditional approaches, such as oral presentations, essays, performances, group projects, peer-assessment, journals, self-assessment, field experiences, oral exams, and portfolios.[1, 2, 3, 7, 8] An open-book exam, although similar to a traditional exam in terms of structure and purpose, may also be considered an alternative assessment since it removes theneed for memorization and makes way for higher-order thinking, problem-solving, and reflection. $[1,6,7,9]$ Traditional methods prevail in higher education despite alternative measures being encouraged and supported empirically as a way to provide students with a more authentic and meaningful learning experience. $[1,4,6]$

The repurposing of traditional, closed-book exams from their usual bricks-and-mortar administration into an online, remote course delivery context is problematic. First, there are many potential inequalities among the geographically separated students, such as: accessibility and affordability of the required hardware, software, and internet connectivity; individual competency and confidence with technology; and access to a quiet, unshared space during the time of an exam. $[7,10]$ Also, the physical separation between the student and the invigilator can amplify the already-present and troublesome issue of academic dishonesty.[7, 11,12,13,14,15] Anti-cheating mechanisms, such as e-proctoring, are complicated and generate concerns about test anxiety and privacy.[16,17] Amidst the rapid growth of online learning in higher education over the past two decades, there is an opportunity to create better alternative exams instead of trying to replicate and enforce the traditional, closed-book conditions online. $[14,18]$

The purpose of this narrative literature review is to explore the suitability of open-book exams as an alternative tool to measure student learning, particularly in the context of online, remote course delivery in higher education. In particular, this review has been undertaken to support the Faculty of Engineering at the University of Alberta with the intention that such information can be of value to both instructors and faculty leadership, i.e., those who develop and implement the exams, as well as make decisions based on the results. The context of this review is one year into the COVID-19 pandemic, a time when perhaps some of the challenges of moving traditional exams to an online environment may be alleviated by instead transitioning to alternative approaches, such as open-book exams. 


\section{METHODOLOGY}

The process undertaken to complete this review was to: (1) identify research questions, (2) determine inclusion criteria, (3) find and organize sources, and (4) conduct a qualitative content analy sis. While it was the authors' early intention to situate this review in an engineering education context, it became evident early in the process that this would not be possible due to a substantial gap in the academic literature. Therefore, the research questions and inclusion criteria were amended to include multidisciplinary works.

\subsection{Research Questions}

The following three research questions informed inclusion criteria and facilitated the locating, organizing, and analyzing of information contained in the sources.

1. What are the merits and limitations of traditional closedbook, in-person exams?

2. What are the merits and limitations of traditional, closed-book exams in an online, remote course delivery context?

3. What are the benefits, concerns, and considerations of transitioning to open-book exams in an online, remote course delivery context?

\subsection{Inclusion Criteria}

Sources considered in this review met the following inclusion criteria:

- Published in a reputable scholarly journal, conference proceeding, or book;

- $\quad$ Presented as a primary source (single empirical study) or secondary source (review, article, or book chapter);

- Published in 1998 or later, since this was the beginning of the rapid growth of online learning using the internet as a delivery mechanism;

- Available online in a digital format, since the accessibility of print copies is hindered at this time due to the pandemic;

- Contained one or more of the following key terms and phrases in the title or abstract: Assessment in higher education, traditional assessment(s) or exams, alternative assessment, open-book exams, academic integrity or cheating.

\subsection{Finding and Organizing Sources}

Primary and secondary sources were located in scholarly publications using the aforementioned key terms and phrases with the following strategies:

- Searching academic databases available through the University of Alberta library website. The most prolific databases were Academic Search Complete and IEEEXplore;
- Manual scanning of reference lists of chosen sources for additional relevant articles;

- Forward searching using Google Scholar to find more recent articles that cited a chosen source.

Digital files (PDFs) of sources were organized into Google Drive folders. Spreadsheet software (Google Sheets) was used to manage bibliographic information and text segments extracted during the qualitative content analysis.

\subsection{Qualitative Content Analysis}

Qualitative methodology is beneficial for exploring and developing an understanding of a central phenomenon, in this case the suitability of open-book exams as an alternative assessment tool, particularly in the context of online, remote course delivery in higher education. A qualitative content analysis is conducted by collecting, reading, and coding the data. These steps are concurrent and iterative in nature.[19]

Upon a first read through all the sources, each was categorized for its strongest alignment with one of the three research questions. Over subsequent readings, relevant text blocks were extracted and organized into a matrix that aligned sources (row headings) and the research questions, themes and subthemes (column headings). The Findings section summarizes the themes and subthemes that emerged from the literature. The text blocks were studied and integrated, and themes and subthemes were used to shape the Discussion section.

Because of the qualitative nature of this review, the findings, discussion, and conclusions are not factual, but rather constructions shaped by the values of the researchers.[20] Efforts toward trustworthiness (quality) of the review were made throughout the data collection, organization, and reporting phases by means such as: care in searching and selecting sources best fitting the research questions and inclusion criteria; revisiting the datatime and time again to ensure accurate representation; and coauthorship for combined expertise and maximal accountability.[20]

\section{FINDINGS}

A collection of 47 sources, comprised of empirical studies, articles, and book chapters, were located and included in this narrative review of the literature. Of note, only six of these sources (13\%) specifically discussed testing culture in engineering education. $[3,11,26,29,31,44]$ Table 1 summarizes the themes and subthemes that emerged in relation to each research question. Numerous merits of traditional closed-book 
exams defend their pervasiveness and longevity across the disciplines in higher education. Conversely, their limitations justify efforts toward alternatives that may better measure students' knowledge and skills. There are points for and against computer-mediated exams, both inperson and remote. While the use of open-book exams in an online, remote learning context can help mitigate issues such as cheating, they are not without concerns and considerations.

Table 1: Emergent themes from the literature, aligned with research questions.

\begin{tabular}{|c|l|}
\hline RQ & \multicolumn{1}{c|}{ Themes and Subthemes } \\
\hline 1 & $\begin{array}{l}\text { There are merits to traditional, closed-book exams } \\
\text { efficient (content coverage); efficient } \\
\text { (administration, marking); objective; diagnostic; } \\
\text { standardized; secure against cheating } \\
\text { There are limitations to the use of traditional, closed- } \\
\text { book exams } \\
\bullet \quad \text { behaviourist; low-level thinking; memorization; } \\
\text { non-authentic; stressful; insecure against cheating }\end{array}$ \\
\hline 2 & $\begin{array}{l}\text { There are merits to computer-mediated traditional } \\
\text { exams, whether in-person or remote } \\
\bullet \quad \text { administrative convenience, scalability, } \\
\text { automaticity and consistency in grading, timely } \\
\text { feedback } \\
\text { accommodations for special needs } \\
\text { multimedia integration } \\
\text { There are limitations to traditional exams } \\
\text { administered online and remotely } \\
\bullet \quad \begin{array}{l}\text { disparities: technical hardware and software; } \\
\text { internet connectivity; technological proficiency; } \\
\text { quiet, unshared space }\end{array} \\
\bullet \begin{array}{l}\text { increased opportunity for cheating } \\
\text { anxiety, privacy concerns with e-proctoring }\end{array} \\
\text { There are benefits of the use of open-book exams in } \\
\text { remote course delivery } \\
\bullet \quad \begin{array}{l}\text { Open-book exams can negate the limitations of } \\
\text { traditional, closed-book exams: constructivist; } \\
\text { authentic; reduced anxiety, increased confidence; } \\
\text { higher-level; no memorization required; cheating } \\
\text { mitigated }\end{array} \\
\text { There are concerns and considerations when using } \\
\text { open-book exams in remote course delivery } \\
\bullet \text { impact on study habits, retention, performance; } \\
\text { need for instructor support }\end{array}$ \\
\hline
\end{tabular}

\section{DISCUSSION}

\subsection{Merits of Traditional, In-person Exams}

Traditional exams (closed-book, in-person, and invigilated) have deep roots in higher education. $[4,5,6,21,22]$ While other methods are in use, traditional exams remain a predominant and steadfast choice across the disciplines.[6] Traditional exams can include short- answer and essay questions, but multiple-choice questions are more common and arguably more objective since there is only one correct answer.[1] The efficiency of multiplechoice questions enables a traditional exam to cover a large number of topics in one sitting.[14] For an institution and an instructor, these assessments are cost-effective due to their ease of administration and marking. $[1,14]$ Traditional exams are diagnostic as they are a means to determine student mastery of content and conceptual understanding. When carefully constructed, the distractors (incorrect responses) of a multiple-choice question can give clues to student misunderstandings and misconceptions.[1] Experiences with traditional exams, while stressful, can help students prepare for high-stakes standardized exams that they may encounter in their future studies and professions.[21] Because traditional exams are invigilated, they are regarded as secure and therefore resistant to unethical student behaviour, namely cheating.[23]

\subsection{Limitations of Traditional, In-person Exams}

Traditional exams are grounded in the behaviourist learning theory, an approach where knowledge is passively transferred to students and committed to memory by a continuous process of reinforcements and feedback.[24] However, because traditional exams are separated from teaching and learning activities (they usually occur at the mid- or end-point of a course), any feedback provided to students is arguably too late to be of any benefit.[25] Students prepare for traditional exams by memorizing factual information, often cramming and limiting their focus to surface learning, only to "data dump" on test day. $[1,2,8,13]$ This exam preparation behaviour arguably lacks authenticity, since it is not congruent with professional skills, such as critical thinking and team work, that students will require for their future careers. $[25,26]$ The high-stakes, closed-book nature of traditional exams is known to generate feelings of anxiety in students, which can negatively affect their performance and result in a mark that does not represent their true abilities.[16, 27]

Despite invigilation, cheating by students on traditional exams that are administered in-person (by "safer" mechanisms such as impersonation, the use of forbidden aids, and peeking) is a reality.[11] Students anonymously admitting to cheating, despite being supervised, cite reasons such as the high-stakes nature of the assessment and a relatively low chance of getting caught and/or punished.[7, 11,28] They weigh the benefits (such as work avoidance, stress alleviation, and higher grades) versus the drawbacks (predominantly the severity of punishment) when deciding if cheating is worthwhile. [29, 30] 


\subsection{Merits of Computer-mediated Traditional Exams, Whether In-person or Remote}

An initial and sudden response to the COVID-19 pandemic was to move traditional exams to a computermediated environment. However, traditional exams have been shifting online, administered both in-person (for example, in computer labs) and remotely, long before 2020.[11, 12, 16, 31] Some benefits of computer-mediated assessments include administrative convenience, scalability, automaticity and consistency in grading, and timely feedback for students.[10,11,12,16,27,31] Special educational needscan be addressed with tools, such as screen magnifiers and readers, or individualized software settings.[12] Some students report a preference for typing rather than handwriting because of decreased muscle fatigue, more time for thinking, and ease of editing.[11] The student experience can be enriched with multimedia embedded into questions, such as videos or simulations, that would not be possible with paper-based exams.[6,12]

\subsection{Limitations to Traditional Exams Administered Online and Remotely}

A number of potential inequalities arise when students are tasked with completing exams individually, in their homes or another space that is physically distanced from the classroom. These include disparities in hardware and software requirements, internet connectivity, individual proficiency with technology, and even the availability of a quiet, unshared space for the duration of the exam. [7, 10]

The physical separation between the student and invigilator is assumed to amplify the already-present act of cheating, and more so if unproctored. [7, 11, 12, 13, 14, 15] Students can attempt "riskier" cheating mechanisms, such as peer collaboration and plagiarism. This concern has mobilized an arsenal of anti-cheating mechanisms for the remote, online testing environment, such as third-party eproctoring services, browser lockdown software, and test settings, such as randomization and shuffling of questions and timing restrictions. Many of these anti-cheating measures are not foolproof, raise anxiety, and perhaps they only send a message that students are not to be trusted.[7, 15]

There are concerns of heightened anxiety and privacy intrusion, particularly with the use of e-proctoring services in an attempt to maintain exam integrity. The educational institution and software vendor gain access to live or recorded video of students' private spaces and biometric data, and it is not clear how long this information is retained and how it will be used.[16,17]

\subsection{Benefits of Open-Book Exams in a Remote Course Delivery Context}

For the most part, the benefits of open-book exams oppose and counteract the limitations of traditional exams discussed previously in this review. Alternative assessments, including open-book exams, are supported by the learning theory of constructivism wherein students have an active role in the acquisition of knowledge through experience and reflection. [4,32] Open-book exams can be summative and rigorous like their closed-book counterparts; however, allowing students to access resources in real-time makes open-book exams well-suited as formative activities for learning.[1]

Alternative assessments are also referred to as "learnercentred" "authentic", and "performance-based", since they characteristically have students actively engaged in activities with real-world relevance that help them build skills necessary for their discipline of study.[2,33,34] Open-book exams can better resemble real-world problem solving and the development of generic attributes. $[6,35]$ Fewer restrictions can provide students with an experience that more closely resembles what they will encounter in a professional setting, i.e., solving problems and making decisions by integrating various sources of information and collaborating with others. $[8,35,36]$

A notable benefit of open-book exams is their impact on student emotions, specifically reduced anxiety and increased confidence.[5,36,37] Allowing the use of resources during an exam, such as the use of notes, textbooks and websites or permission to collaborate with peers, is a form of cognitive offloading that can offer emotional and performance benefits as compared to exams with closed-book restrictions.[38] While an instructor still needs to make it clear what cognitive tools are allowed, students report feeling less anxious and more optimistic and relaxed when taking an open-book exam. A sense of calm and control in this situation has been shown to positively impact brain function.[36] The flexibility of place and time that open-book exams can provide may ease pressure on students who are balancing their studies with other commitments, such as work and family.[39]

Open-book exams can simultaneously mitigate cheating if they challenge students with questions targeting higher-order thinking. $[5,6,13]$ Certain types of exam questions are more susceptible to cheating than others in an open-book context. Answers to basic knowledge and common math or science problems can be easily located in a textbook or searched for online.[7, 14, 15] General long answer or essay questions can invite plagiarism or the use of an essay mill.[18] However, when certain resources are permitted during an exam (and memorization is not required), students can be challenged with questions that require higher-order thinking, such as analyzing and evaluating information, and the self-formulation of responses.[5,13,14,36] In this regard, whether in 
multiple-choice or written formats, cheating is negated, as is possibly the need for invigilation.[36]

\subsection{Concerns and Considerations of Open-book Exams in a Remote Course Delivery Context}

Academic literature is divided on the effect of closedor open-book exam formats on student study habits (preexam preparation and subsequent long-term retention of information) and exam performance. $[35,40]$ Students may devote more effort into studying for closed-book exams since they know they will not be able to access resources during the exam and that the controlled nature of the exam administration stifles any cheating attempts. $[6,8,15]$ Students may better prepare for an open-book exam, because they know that cramming and memorization won't provide the required level of conceptual understanding. [8, 36, 37] Alternatively, students may be over-confident and dedicate less effort into studying for an open-book exam, because they feel they can "wing it" and hunt for answers during the test. [5, 6, 15] Authors correlate long-term retention of information to the effort and depth of pre-exam preparation in either format. Students may perform better on open-book exams, because they have acquired a deeper learning of the material when studying, or simply because they have real-time help from resources and peers. $[5,13,40]$ Alternatively, students may perform worse on open-book exams, because they underestimated the difficulty of the questions, or they spend too much time hunting for information rather than formulating their responses.[27,37]

From an instructor perspective, implementing an openbook exam is not as simple as repurposing a closed-book exam yet permitting students access to resources and peers during the exam. Questions best suited to an open-book context go beyond basic recall, targeting higher-order thinking and real-world problem solving. These question types, however, are therefore more challenging to construct and onerous to mark. Also, teaching strategies need to align with helping students prepare for an exam of this nature. With these considerations in mind, instructors require training, resources, and ongoing support in their endeavour to develop and administer quality open-book exams.[35]

\section{CONCLUSION}

Assessment is at the core of the learning process and student experience in post-secondary education. Traditional exams are commonplace despite the alternative methods being championed for their student-centered nature and alignment with a constructivist learning theory. This narrative review of the literature aimed to compare traditional and alternative exams with points of consideration being closed vs. open-book, paper-based vs. computer-mediated, and invigilated vs. unsupervised. While it was envisioned for this review to focus on engineering education, a gap in the literature was identified and sources representing multiple higher education disciplines were included. Traditional closed-book, invigilated exams using predominantly multiple-choice questions are regarded as beneficial for their efficiency, objectivity, and security, but can be problematic when moved to an online, remote setting with e-proctoring. Alternative open-book exams can alleviate some concerns (namely student anxiety and cheating) and are arguably more authentic because they better resemble the critical thinking and problem-solving processes students will use in their future studies and careers.

The issue of academic integrity was threaded through the literature with no definite verdict for how it could be best approached or prevented. The literature was also found to be inconclusive about how varying assessment modalities impact student study habits and performance. Nonetheless, information drawn from the 47 sources in this review, six with a focus on engineering education, can contribute to informed decision-making about exam methods best suited to specific online, remote course contexts in higher education.

\section{Acknowledgements}

This review of the literature on traditional versus openbook exams was supported by the Faculty of Engineering at the University of Alberta.

\section{References}

[1] L. A. Suskie, Assessing student learning: A common sense guide, San Francisco, CA: Jossey-Bass, 2018.

[2] D. Conrad and J. Openo, Assessment strategies for online learning: Engagement and authenticity, Edmonton: Athabasca University Press, 2018.

[3] P. J. Gray, "Student learning assessment," in Rethinking engineering education: The CDIO approach, Boston, Springer, 2007, pp. 152-165.

[4] E. Nordmann, C. Horlin, J. Hutchison, J.-A. Murray, L. Robson, M. K. Seery and J. R. D. MacKay, "Ten simple rules for supporting a temporary online pivot in higher education," PLoS Computational Biology, vol. 16, no. 10, p.e1008242, 2020.

[5] K. Michael, E. Lyden and T. Custer, "Open-book examinations (OBEs) in an ultrasound physics course: A good idea or a bad experiment?," Journal of Diagnostic Medical Sonography, vol. 35, no. 3, pp. 174-180, 2019.

[6] S. Bloxham and P. Boyd, Developing effective assessment in higher education: A practical guide, McGraw-Hill Education, 2007.

[7] R. Fuller, V. Joynes, J. Cooper, K. Boursicot and T. Roberts, "Could COVID-19 be our 'there is no 
alternative' (TINA) opportunity to enhance assessment?," Medical Teacher, vol. 42, no. 7, pp. 781-786, 2020.

[8] B. Johanns, A. Dinkens and J. Moore, "A systematic review comparing open-book and closed-book examinations: Evaluating effects on development of critical thinking skills," Nurse Education in Practice, vol. 27,pp. 89-94, 2017.

[9] D. Carless, "Exploring learning-oriented assessment processes," Higher Education, vol. 69, pp.963-976, 2015.

[10] N. Alruwais, G. Wills and M. Wald, "Advantages and challenges of using e-Assessment," International Journal of Information and Education Technology, vol. 8, no. 1, pp. 34-37, 2018.

[11] A. Chirumamilla, G. Sindre and A. Nguyen-Duc, "Cheating in e-exams and paper exams: The perceptions of engineering students and teachers in Norway," Assessment \& Evaluation in Higher Education, vol.45, no. 7, pp. 940-957, 2020.

[12] A. E. Fluck, "An international review of eExam technologies and impact," Computers \& Education, p. $15 \mathrm{pp}, 2019$.

[13] D. López, J.-L. Cruz and F. Sánchez, "A take-home exam to assess professional skills," in 41st ASEE/IEEE Frontiers in Education Conference, Rapid City, SD, 2011.

[14] J. G. Nguyen, K. J. Keuseman and J. J. Humston, "Minimize online cheating for online assessments during COVID-19 pandemic," Journal of Chemical Education, vol.97, pp. 3429-3435, 2020.

[15] O. Senkova, H. Otani, R. L. Skeel and R.L. Babcock, "Testing effect: A further examination of open-book and closed-book test formats," Journal of Effective Teaching in Higher Education, vol. 1, no. 1, pp. 2036, 2018.

[16] D. Woldeab and T. Brothen, "21st century assessment: Online proctoring, test anxiety, and student performance," International Journal of ELearning \& Distance Education, vol. 34, no. 1, p. 10pp, 2019.

[17] M. Halaweh, "Are universities using the right assessment tools during the pandemic and crisis times?," Higher Learning Research Communications, vol. 11, no. 0, pp. 1-9, 2020.

[18] J. Johnston and C. O'Farrell, "Rewriting the (exam) script? Assessing student learning in an unusual endof-year context," All Ireland Journal of Teaching and Learning in Higher Education, vol. 12, no. 2, p. $13 \mathrm{pp}, 2020$.

[19] J. W. Creswel, Educational research: Planning, conducting, and evaluating quantitative and qualitative research, 5th ed., Boston: Pearson Education, 2015.

[20] E. G. Guba and Y. S. Lincoln, Fourth generation evaluation, Sage Publications, Inc, 1989.

[21] A. Kolomuc, "Subject-specific science teachers' views of alternative assessment," Asia-Pacific Forum on Science Learning and Teaching, vol. 18, no. 5, p. 18pp, 2017.

[22] J. B. Williams and A. Wong, "The efficacy of final examination: A comparative study of closed-book, invigilated exams and open-book, open-web exams," British Journal of Educational Technology, vol. 40, no. 2, pp. 227-236, 2009.

[23] L. Bengtsson, "Take-home exams in higher education: A systematic review," Education Sciences, vol.9, no. 4, pp. 267-283, 2019.

[24] S. Ahmad, N. Sultana and S. Jamil, "Behaviorism vs constructivism: A paradigm shift from traditional to alternative assessment techniques," Journal of Applied Linguistics and Language Research, vol. 7, no. 2, pp. 19-33, 2020.

[25] T. L. Larkin, "Breaking with tradition: Using the conference paper as a case for alternative assessment in physics," in 2013 International Conference on Interactive Collaborative Learning (ICL), Kazan, Russia, 2013.

[26] S. Palmer, "Authenticity in assessment: Reflecting undergraduate study and professional practice," European Journal of Engineering Education, vol. 29, no. 2, pp. 193-202, 2004.

[27] J. Tao and Z. Li, "A case study on computerized takehome testing: Benefits and pitfalls," International Journal of Technology in Teaching and Learning, vol. 8, no. 10,pp. 33-43, 2012.

[28] D. Steger, U. Schroeders and T. Gnambs, "A metaanalysis of test scores in proctored and unproctored ability assessments," European Journal of Psychological Assessment, vol. 36, no. 1, pp. 174$184,2020$.

[29] H. J. Passow, M. J. Mayhew, C. J. Finelli, T. S. Harding and D. D. Carpenter, "Factors influencing engineering students' decisions to cheat by type of assessment," Research in Higher Education, vol. 47, no. 6, pp. 643-684, 2006.

[30] P. A. Hutton, "Understanding student cheating and what educators can do about it," College Teaching, vol. 54, no. 1, pp. 171-176, 2006.

[31] K. Andersenn, S. E. Thorsteinsson, H. Thorbergsson and K. S. Gudmundsson, "Evaluating learning outcomes in online exams through alternative assessments," in 29th Annual Conference of the European Association for Education in Electrical 
and Information Engineering (EAEEIE), Ruse, Bulgaria, 2019.

[32] S. O. Bada, "Constructivism learning theory: A paradigm for teaching and learning," Journal of Research \& Method in Education, vol. 5, no. 6, pp. 66-70, 2015.

[33] B. B. Frey, V. L. Schmitt and J. P. Allen, "Defining authentic classroom assessment," Practical Assessment Research \& Evaluation, vol. 17, no. 2, pp. 1-18, 2012.

[34] K. Sambell, L. McDowell and C. Montgomery, Assessment for learning in higher education, Routledge, 2013.

[35] S. G. Green, C. J. Ferrante and K. A. Heppard, "Using open-book exams to enhance student learning, performance, and motivation," The Journal of Effective Teaching, vol. 16, no. 1, pp. 19-35, 2016.

[36] L. Myyry and T. Joutsenvirta, "Open-book, openweb online examinations: Developing examination practices to support university students' learning and self-efficacy," Active Learning in Higher Education, vol. 16, no. 2, pp. 119-132, 2015.

[37] A. Gharib, W. Phillips and N. Mathew, "Cheat sheet or open-book? A comparison of the effects of exam types on performance, retention, and anxiety," Psychology Research, vol. 2, no. 8, pp. 469-478, 2012.

[38] P. Dawson, "Cognitive offloading and assessment," in Re-imagining university assessment in a digital world, Cham, Springer, 2020, pp. 37-48.

[39] K. Butler-Henderson and J. Crawford, "A systematic review of online examinations: A pedagogical innovation for scalable authentication and integrity," Computers \& Education, vol. 159, p. 12pp, 2020.

[40] S. Brallier and L. Palm, "Proctored and unproctored test performance," International Journal of Teaching and Learning in Higher Education, vol. 27, no. 2,pp. 221-226, 2015.

[41] L. Norton, B. Norton and L. Shannon, "Revitalising assessment design: What is holding new lecturers back?," Higher Education, vol. 66, no. 2, pp. 233251, 2013.

[42] H. E. Kentnor, "Distance education and the evolution of online learning in the United States," Curriculum and Teaching Dialogue, vol. 17, no. 1,2, pp. 21-34, 2015.

[43] N. Holmes, "Engaging with assessment: Increasing student engagement through continuous assessment," Active Learning in Higher Education, vol. 19, no. 1, pp. 23-34, 2018.

[44] I. Gratchev and D.-S. Jeng, "Introducing a projectbased assignment into a traditionally taught engineering course," European Journal of Engineering Education, vol. 43, no. 5, pp. 788-799, 2018.

[45] S. E. Eaton, "Academic integrity during COVID-19: Reflections from the University of Calgary," International Studies in Educational Administration, vol. 48, no. 1, pp. 80-85, 2020.

[46] L. W. Daffin and A. A. Jones, "Comparing student performance on proctored and non-proctored exams in online psychology courses," Online Learning, vol. 22, no. 1, pp. 131-145, 2018.

[47] M. Borrega, M.J. Foster and J.E. Froyd, "Systematic literature reviews in engineering education and other developing interdisciplinary fields," Journal of Engineering Education, vol. 103, no. 7, pp. 45-76, 2014.

[48] B. Boitshwarelo, A. K. Reedy and T. Billany, "Envisioning the use of online tests in assessing twenty-first century learning: A literature review," Research and Practice in Technology Enhanced Learning, vol. 12, no. 16, p. 16pp, 2017.

[49] C. Böhmer, N. Feldmann and M. Ibsen, "E-exams in engineering education - Online testing of engineering competencies," in IEEE Global Engineering Education Conference (EDUCON), Santa Cruz de Tenerife, Canary Islands, Spain, 2018. 